\title{
Compact Triple-Band Antenna Employing Simplified MTLs for Wireless Applications
}

\author{
Zhangjing Wang, Yang Peng, and Yahua Ran \\ School of Electronic Engineering, University of Electronic Science and Technology of China, Chengdu 611731, China \\ Correspondence should be addressed to Yang Peng; 707410537@qq.com
}

Received 5 November 2015; Accepted 20 January 2016

Academic Editor: Paolo Burghignoli

Copyright (C) 2016 Zhangjing Wang et al. This is an open access article distributed under the Creative Commons Attribution License, which permits unrestricted use, distribution, and reproduction in any medium, provided the original work is properly cited.

A compact triple-band asymmetric coplanar waveguide- (ACPW-) fed antenna based on simplified metamaterial transmission lines (SMTLs) is proposed in this paper. The antenna consists of two SMTL unit cells of the same dimension. Three operating bands, which cover UMTS in the $1.76 \mathrm{GHz}$ band and WLAN in the $5.2 \mathrm{GHz}$ and $5.8 \mathrm{GHz}$, are achieved when the zeroth-order and firstpositive-order modes appear. The characteristics of the proposed transmission line metamaterial structure are studied in detail by circuit analysis and dispersion analysis. The working mechanism and radiation performances of the antenna are examined and illustrated at the three operating bands, respectively. A prototype designed on FR4 substrate with dielectric constant 4.3 occupies an overall size of $12.55 \times 22.7 \times 1.6 \mathrm{~mm}^{3}$ and is constructed and successfully measured.

\section{Introduction}

The majority of modern communication applications need portable devices which are able to operate at multiple frequency bands, so the multiband operation antenna with compact size, low cost, and ease of integration is urgently needed. Different approaches used to design multiband antennas have been reported. The traditional approaches to achieve multiband operation are using multiple metallic strips $[1,2]$, with cutting various shape slots $[3,4]$ in the radiating patch and adding subpatches to main patch to create multiband functions $[5,6]$. However, the traditional methods may increase cost; the structure is complicated to be fabricated; the overall dimension of the antenna is large and it may create undesired radiation from parasitic elements. Recently, metamaterial has been paid more attention to implement multiband functions of antenna. Some multiband antennas loaded with composite right/left-handed (CRLH) unit cell were shown in [7-9]. By loading various shape monopole antennas with different number of CRLH unit cells, new operating bands appear, while the original band created by monopole antenna still existed. However, these cells also help to reduce the original band of the monopole antenna. At the same time, the CRLH unit cells may contribute to the radiation as the main antenna is not an efficient radiator and lead to complicated structure. In [10], a frequency reconfigurable metamaterial inspired antenna was presented. By replacing the interdigital capacitor with a varactor diode, the higher band of the antenna remains effectively constant while the lower band of the antenna is tuning. The DC bias circuit, however, is lossless and too complicated. In [11-14], compact multiband antennas with single-cell metamaterial loading were reported and their working principle was similar to those of [7-9], except those in [12,13], a band of which was attained by cutting a slot on ground or patch. The performance is good but the antennas are not compact enough.

In this paper, a compact triple-band antenna employing simplified MTLs for wireless application is presented. An asymmetric coplanar waveguide is used to reduce the antenna dimension and this method was proposed in [15], which presented a bisected zeroth-order resonator antenna designed by dissecting the initial design by half. The series capacitors decrease with the equivalent inductor and resistance increases, so that great miniaturization and increase of bandwidth and efficiency are obtained. Different from 
[15], the antenna involved in this paper only has halfground plane, with the radiation area still remaining. Thus a miniaturized antenna is obtained without affecting the other properties significantly. By using the zeroth-order and firstpositive resonance mode at the same time, a triple-band operation function is obtained.

\section{Antenna Design}

Figure 1 illustrates the geometry of the proposed triple-band antenna. The antenna is printed on the top layer of the FR4 substrate with 4.3 relative dielectric constant and $12.55 \times$ $22.7 \times 1.6 \mathrm{~mm}^{3}$ dimension. The asymmetric coplanar strip feed is analogous to the coplanar wave guide feed which is used for reducing the size of the designed antenna. The CPW-fed line is employed to match the antenna to the 50$\Omega$ cable. The left-hand series capacitance $C_{L}$ is formed using interdigital gap which is etched on the host patch and the right-hand shunt capacitance $C_{R}$ is formed from the electric field between the radiator patch and ground plane; the righthand series inductance $L_{R}$ results from the current flow on the patch. An effective equivalent circuit for the designed SMTLs is depicted in Figure 2. The series impedance $Z$ and shunt admittance $Y$ in Figure 2 can be obtained as

$$
\begin{aligned}
& Z=R+j w L_{R}+\frac{1}{j w C_{L}}, \\
& Y=G+j w C_{R},
\end{aligned}
$$

where $R$ and $G$ are the series resistance and shunt conductance of the lossy transmission line, respectively. For a transmission line under lossless and shorted-end condition, the imaginary part of input impedance $Z_{\text {in }}$ is zero at series resonant frequency. So the zeroth-order resonance (ZOR) frequency is given by

$$
w=\frac{1}{\sqrt{C_{L} L_{R}}} .
$$

The dispersion diagram can be obtained by applying BlochFloquet theory [16] as in the following equation:

$$
\beta(w)=\frac{1}{l} \cos ^{-1}\left(\frac{1-S_{11} S_{22}+S_{12} S_{21}}{2 S_{21}}\right),
$$

where $l$ is the length of the unit cell. $\beta$ is the propagation constant for Bloch waves which can be derived from ABCD matrix theory [17]. The dispersion diagram of the metamaterial unit cell is shown in Figure 3. In theory, for the lossless cases, the threshold frequency, at $\beta=0$, is known as the zeroth-order resonant frequency. But in this paper, the losses within the host CPW have been considered, the zeroth-order resonant frequency which appeared around $1.76 \mathrm{GHz}$, while $\beta$ is not exactly zero.

Figure 4 shows the simulated $S_{11}$ with different values of $l_{2}$; it can be seen that the zeroth-order resonant frequency increases from 1.69 to $1.89 \mathrm{GHz}$ as the interdigital finger length $\left(l_{2}\right)$ decreases from 6.5 to $4.5 \mathrm{~mm}$. This outcome is from the decrease of $l_{2}$ which in turn provides decreased

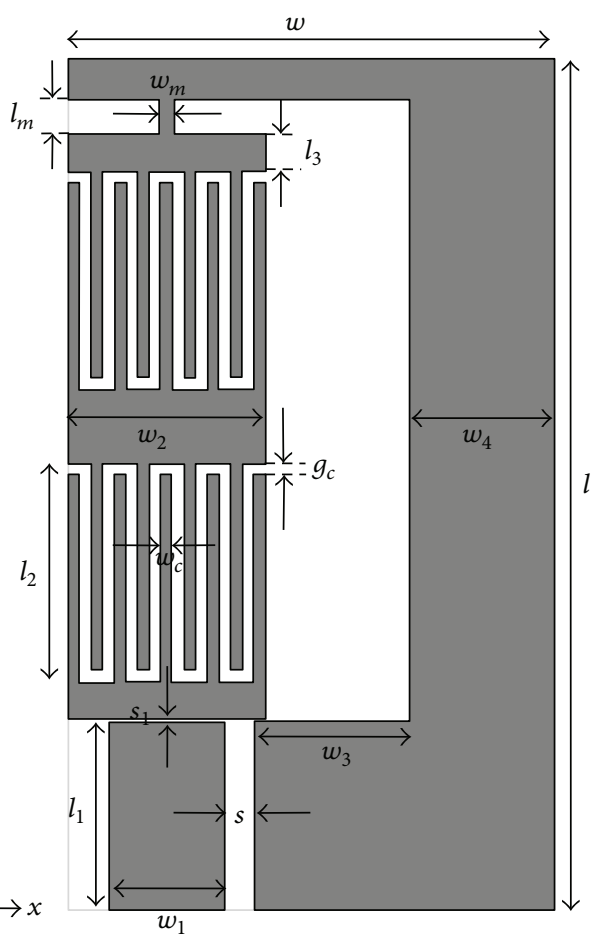

FIGURE 1: Geometry of the proposed antenna.

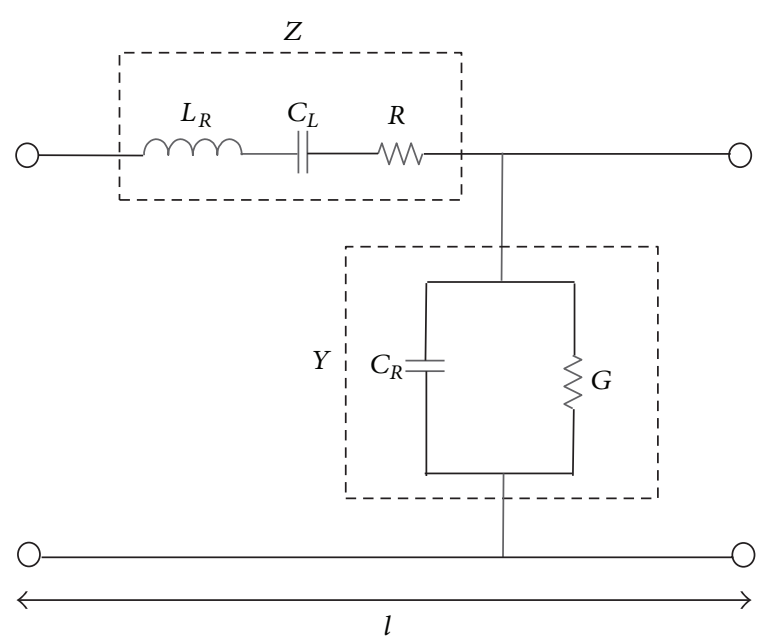

FIGURE 2: Equivalent circuit of the SMTL unit cell.

series capacitance $C_{L}$. According to (2), the resonant frequency will be increased. Therefore, the resonant frequency can be increased by decreasing the length of interdigital finger.

Figure 5 shows the simulated $S_{11}$ with different values of $l_{3}$; it can be seen that the two higher resonant frequencies decrease from 5.26 to $5.1 \mathrm{GHz}$ and 5.86 to $5.59 \mathrm{GHz}$, respectively, as the length $\left(l_{2}+2 * l_{3}\right)$ of the radiation patch increases. Because the increase of $l_{2}+2 * l_{3}$ provides longer effective current length, which will be depicted in Figures 8(b) and $8(\mathrm{c})$, the resonant frequency will be decreased. However, 


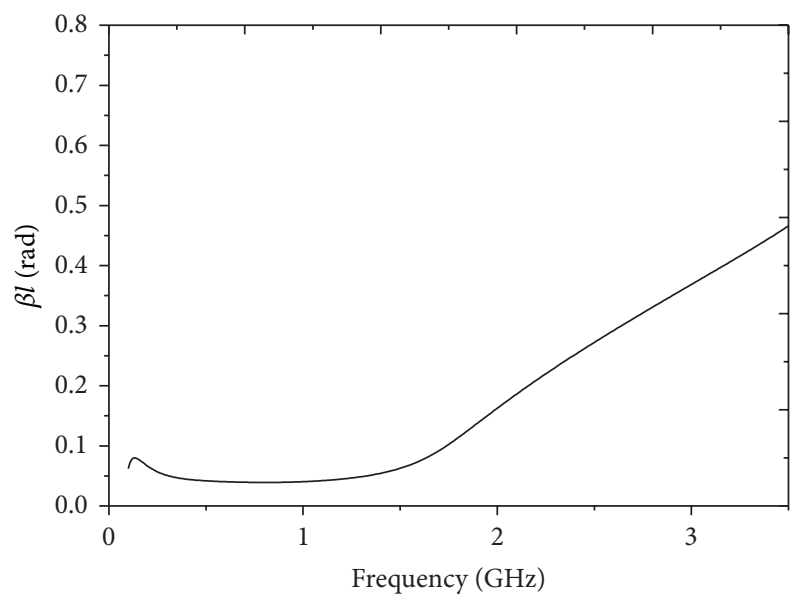

FIgURE 3: Dispersion diagram of the metamaterial unit cell.

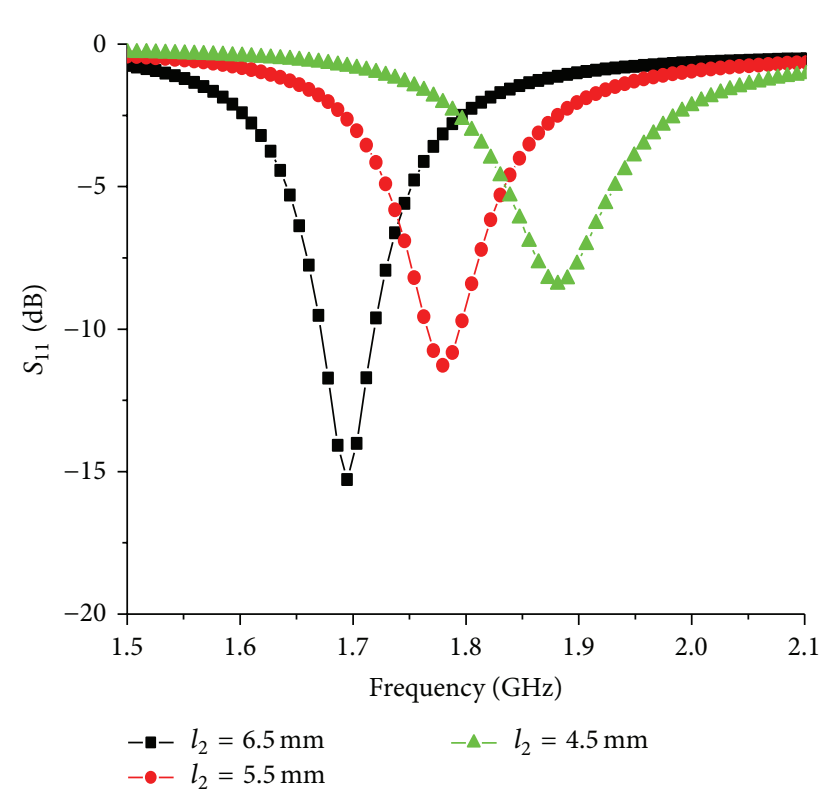

FIGURE 4: Simulated $\left|S_{11}\right|$ for antenna operating at various $l_{2}$.

TABLE 1: Optimal dimensions of the designed antenna.

\begin{tabular}{lccc}
\hline Parameters & Value $(\mathrm{mm})$ & Parameters & Value $(\mathrm{mm})$ \\
\hline$l$ & 22.7 & $w_{c}$ & 0.3 \\
$l_{1}$ & 5 & $w$ & 12.55 \\
$l_{2}$ & 5.8 & $w_{1}$ & 3 \\
$l_{3}$ & 1 & $w_{2}$ & 5.1 \\
$l_{m}$ & 0.9 & $w_{3}$ & 4 \\
$s$ & 0.8 & $w_{4}$ & 3.7 \\
$s_{1}$ & 0.1 & $w_{m}$ & 0.4 \\
$g_{c}$ & 0.3 & & \\
\hline
\end{tabular}

the increase of $l_{3}$ provides increased series inductance $L_{R}$, and according to (2), the zeroth-order resonant frequency is almost decreased.

The optimized parameters of the antenna are listed in Table 1 .

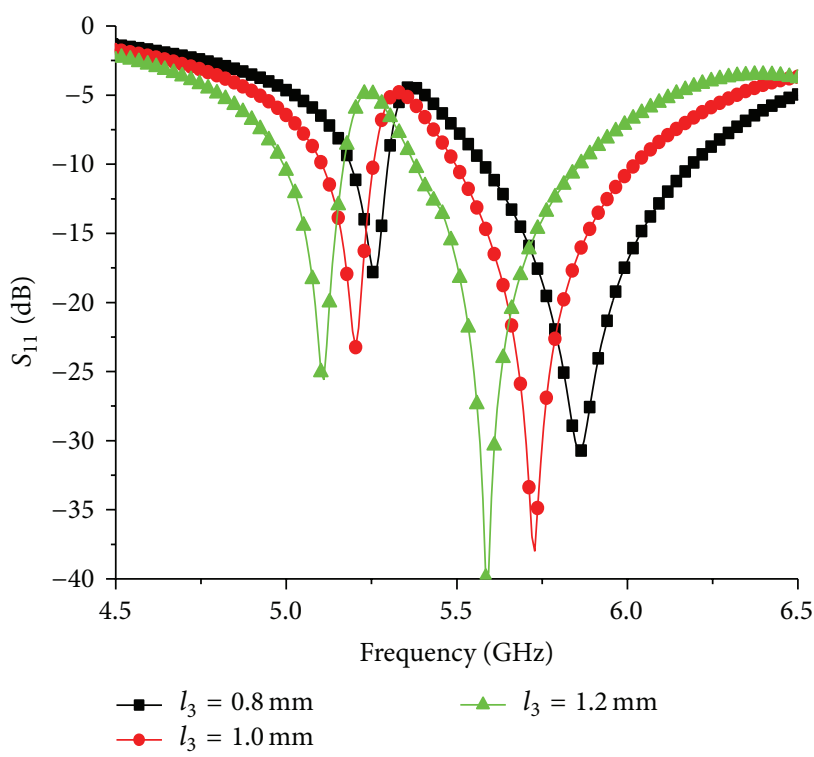

FIGURE 5: Simulated $\left|S_{11}\right|$ for antenna operating at various $l_{3}$.

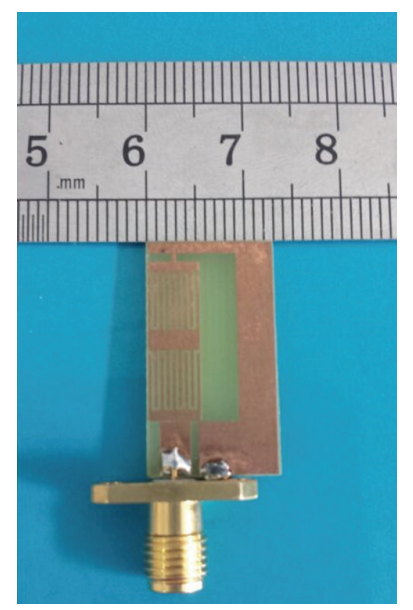

FIGURE 6: Photographs of the fabricated antenna.

\section{Results and Discussion}

In order to investigate the performance of the proposed antenna, a prototype has been fabricated and tested, and its photograph is depicted in Figure 6. Simulated and measured reflection coefficients of the proposed antenna are plotted in Figure 7. The antenna was simulated by using the High Frequency Structure Simulator (HFSS) and measured by a network analyzer. As it can be seen from Figure 7, the measured operating frequencies cover the band of $1.75-1.78 \mathrm{GHz}, 5.2-$ $5.5 \mathrm{GHz}$, and 5.7-6 GHz. The discrepancy between the simulation and measurement may be attributed to the fabrication imperfection, substrate losses, measurement circumstance, and the influence of coaxial connector. 


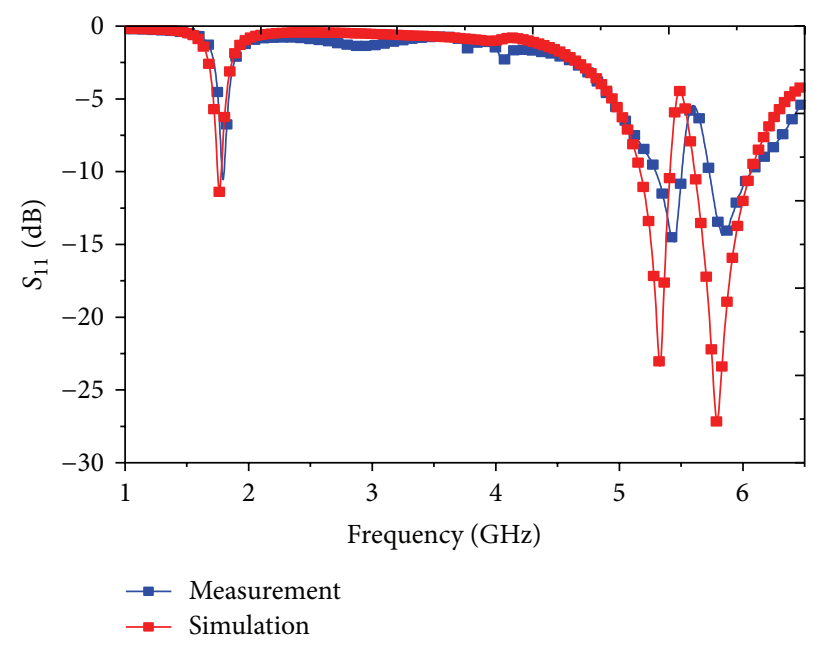

Figure 7: Simulated and measured $\left|S_{11}\right|$ of the proposed antenna.

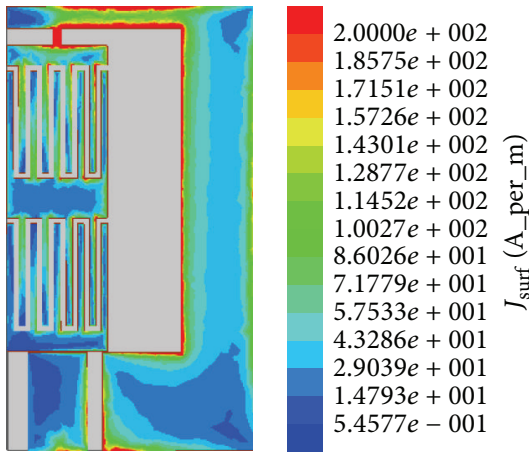

(a) $1.76 \mathrm{GHz}$

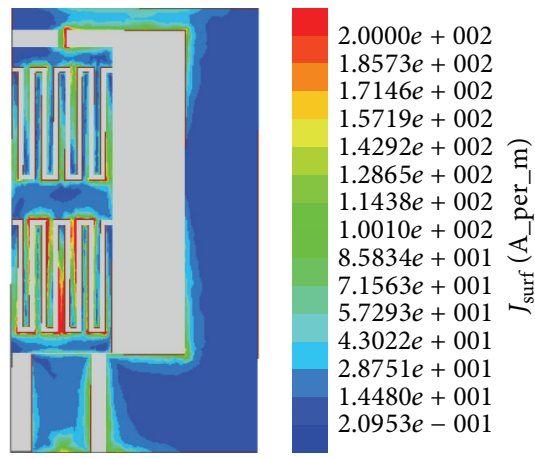

(b) $5.2 \mathrm{GHz}$

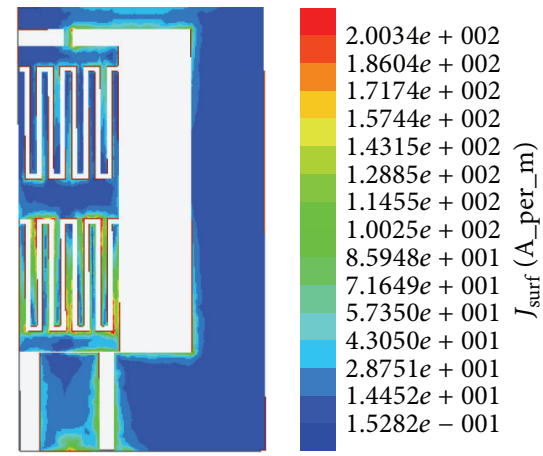

(c) $5.8 \mathrm{GHz}$

FIGURE 8: Simulated current distributions of the proposed antenna at (a) $1.76 \mathrm{GHz}$, (b) $5.2 \mathrm{GHz}$, and (c) $5.8 \mathrm{GHz}$.

In order to get a deep insight into the working principle of the antenna, Figure 8 presents the current distributions of the antenna at 1.76, 5.2, and 5.8 GHz. As shown in Figure 8(a), a relatively uniform current distribution on the radiating patch at $1.76 \mathrm{GHz}$ is one of the complex features of the zerothorder resonance. The resonant frequency of 5.2 and $5.8 \mathrm{GHz}$ was produced by the radiation patch. It can be observed in Figure 8(b) that the current mainly concentrated on the radiating patch and it is larger on the lower metamaterial unit cell while the current is becoming weaker in Figure 8(c). Thus, the value of the coupled capacitor and inductance in Figure 8(c) is smaller than that in Figure 8(b). According to the equation

$$
f=\frac{1}{2 \pi \sqrt{L C}}
$$

when $L$ and $C$ become larger, the resonant frequency will shift lower. So the resonant frequency increased in Figure 8(c).

Figure 9 shows the simulated and measured normalized far-field radiation pattern in $x y$-plane (E-plane) and $x z$-plane
( $H$-plane) at 1.76, 5.2, and $5.8 \mathrm{GHz}$, respectively. The radiation pattern is omnidirectional in the $H$-plane and monopolelike in the $E$-plane. The measured gains are about $0.436,1.1$, and $1.9 \mathrm{dBi}$ at $1.76,5.2$, and $5.8 \mathrm{GHz}$, respectively. And the measured radiation efficiency is $61.4 \%$ at $1.76 \mathrm{GHz}, 73.1 \%$ at $5.2 \mathrm{GHz}$, and $80.3 \%$ at $5.8 \mathrm{GHz}$.

\section{Conclusion}

A compact triple-band antenna based on simplified metamaterial transmission lines has been proposed. With the transmission line metamaterial structure, this antenna could operate at zeroth-order resonance modes. At higher frequency, the antenna acts similarly to a printed monopole and other two operation bands can be achieved. The antenna operates at three frequency bands with monopolar radiation pattern characteristics. Low-profile, simple fabrication, and multiband performance make the proposed antenna a good candidate for numerical wireless applications. 


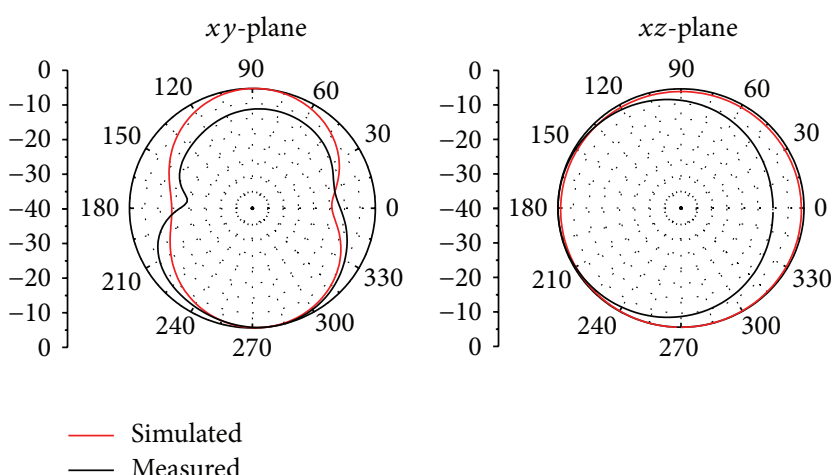

(a)

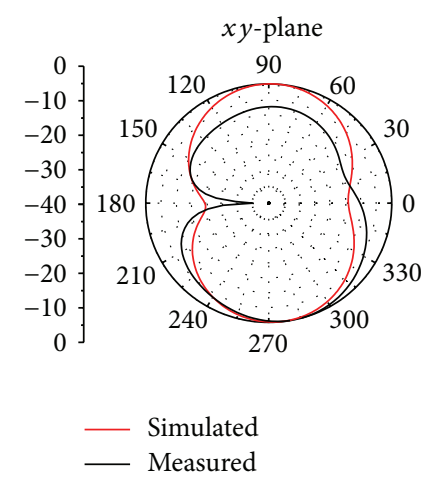

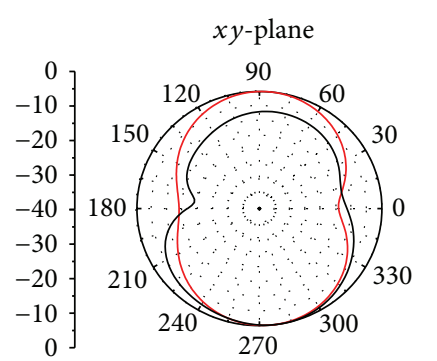

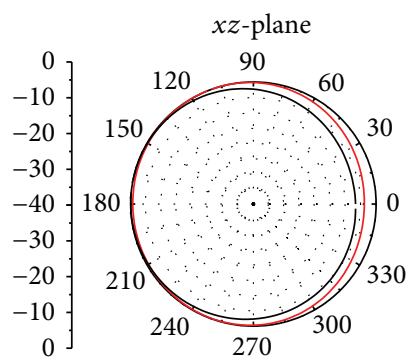

(b)

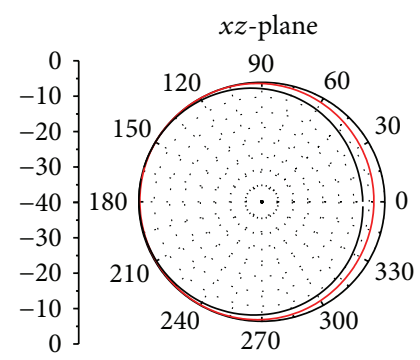

(c)

FIGURE 9: Simulated and measured normalized radiation patterns for the proposed antenna at (a) $1.76 \mathrm{GHz}$, (b) $5.2 \mathrm{GHz}$, and (c) $5.8 \mathrm{GHz}$.

\section{Conflict of Interests}

The authors declare that there is no conflict of interests regarding the publication of this paper.

\section{References}

[1] R. L. Li, X. L. Quan, Y. H. Cui, and M. M. Tentzeris, "Directional triple-band planar antenna for WLAN/WiMax access points," Electronics Letters, vol. 48, no. 6, pp. 305-306, 2012.

[2] Y. Xu, Y.-C. Jiao, and Y.-C. Luan, "Compact CPW-fed printed monopole antenna with triple-band characteristics for WLAN/WiMAX applications," Electronics Letters, vol. 48, no. 24, pp. 1519-1520, 2012.

[3] H. Zhai, Z. Ma, Y. Han, and C. Liang, "A compact printed antenna for triple-band WLAN/WiMAX applications," IEEE Antennas and Wireless Propagation Letters, vol. 12, pp. 65-68, 2013.

[4] S. T. Fan, Y. Z. Yin, W. Hu, K. Song, and B. Li, "Novel CPW-FED printed monopole antenna with an n-shaped slot for dual-band operations," Microwave and Optical Technology Letters, vol. 54, no. 1, pp. 240-242, 2012.

[5] H. F. Abutarboush, R. Nilavalan, S. W. Cheung et al., "A reconfigurable wideband and multiband antenna using dualpatch elements for compact wireless devices," IEEE Transactions on Antennas and Propagation, vol. 60, no. 1, pp. 36-43, 2012.

[6] H. F. AbuTarboush, R. Nilavalan, S. W. Cheung, and K. M. Nasr, "Compact printed multiband antenna with independent setting suitable for fixed and reconfigurable wireless communication systems," IEEE Transactions on Antennas and Propagation, vol. 60, no. 8, pp. 3867-3874, 2012.

[7] A. A. Ibrahim, A. M. E. Safwat, and H. El-Hennawy, "Tripleband microstrip-fed monopole antenna loaded with CRLH unit cell," IEEE Antennas and Wireless Propagation Letters, vol. 10, pp. 1547-1550, 2011.

[8] A. A. Ibrahim and A. M. E. Safwat, "Microstrip-fed monopole antennas loaded with CRLH unit cells," IEEE Transactions on Antennas and Propagation, vol. 60, no. 9, pp. 4027-4036, 2012.

[9] J. Zhu and G. V. Eleftheriades, "Dual-band metamaterialinspired small monopole antenna for WiFi applications," Electronics Letters, vol. 45, no. 22, pp. 1104-1106, 2009.

[10] H. Mirzaei and G. V. Eleftheriades, "A compact frequencyreconfigurable metamaterial-inspired antenna," IEEE Antennas and Wireless Propagation Letters, vol. 10, pp. 1154-1157, 2011.

[11] M. A. Antoniades and G. V. Eleftheriades, "A broadband dualmode monopole antenna using NRI-TL metamaterial loading," IEEE Antennas and Wireless Propagation Letters, vol. 8, pp. 258261, 2009.

[12] J. Zhu, M. A. Antoniades, and G. V. Eleftheriades, "A tri-band compact metamaterial-loaded monopole antenna for WiFi and WiMAX applications," in Proceedings of the IEEE Antennas and Propagation Society International Symposium, pp. 1-4, IEEE, Charleston, SC, USA, June 2009.

[13] H. Huang, Y. Liu, S. Zhang, and S. Gong, "Multiband metamaterial-loaded monopole antenna for WLAN/WiMAX applications," IEEE Antennas and Wireless Propagation Letters, vol. 14, pp. 662-665, 2015.

[14] S. Jamilan, M. A. Antoniades, J. Nourinia, and M. N. Azarmanesh, "A directivity-band-dependent triple-band and 
wideband dual-polarized monopole antenna loaded with a viafree CRLH unit cell," IEEE Antennas and Wireless Propagation Letters, vol. 14, pp. 855-858, 2015.

[15] S.-Y. Yang and M. N. M. Kehn, "A bisected miniaturized ZOR antenna with increased bandwidth and radiation efficiency," IEEE Antennas and Wireless Propagation Letters, vol. 12, pp. 159$162,2013$.

[16] A. Lai, K. M. K. H. Leong, and T. Itoh, "Infinite wavelength resonant antennas with monopolar radiation pattern based on periodic structures," IEEE Transactions on Antennas and Propagation, vol. 55, no. 3, pp. 868-876, 2007.

[17] D. M. Pozar, Microwave Engineering, John Wiley \& Sons, New York, NY, USA, 2nd edition, 1998. 


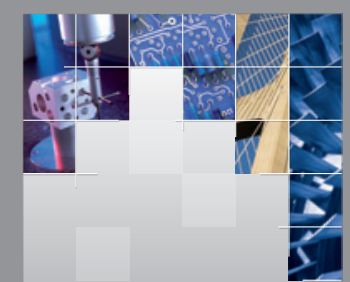

\section{Enfincering}
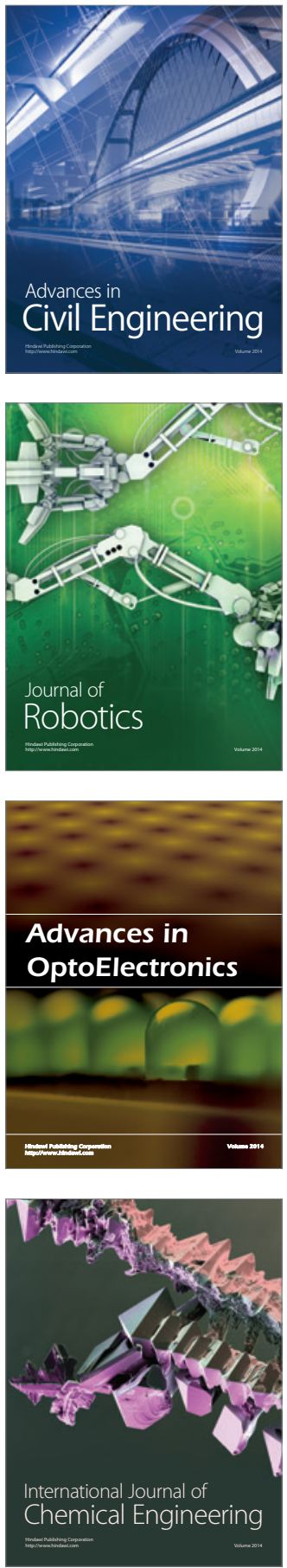

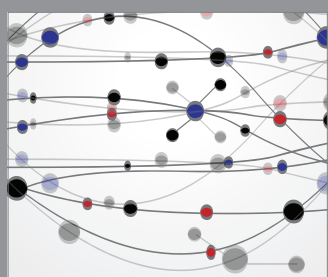

The Scientific World Journal

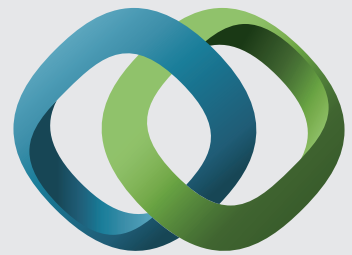

\section{Hindawi}

Submit your manuscripts at

http://www.hindawi.com
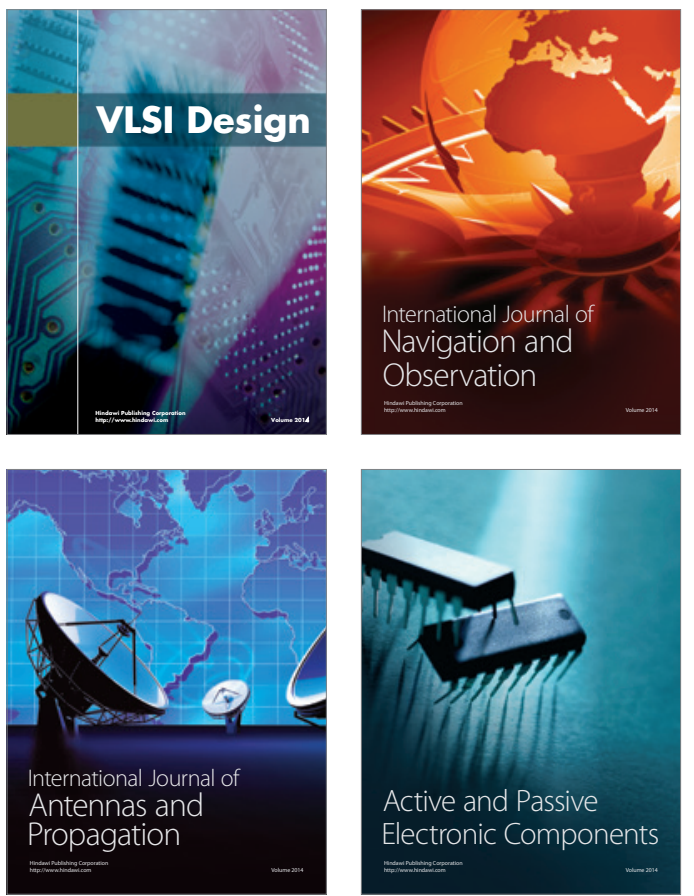
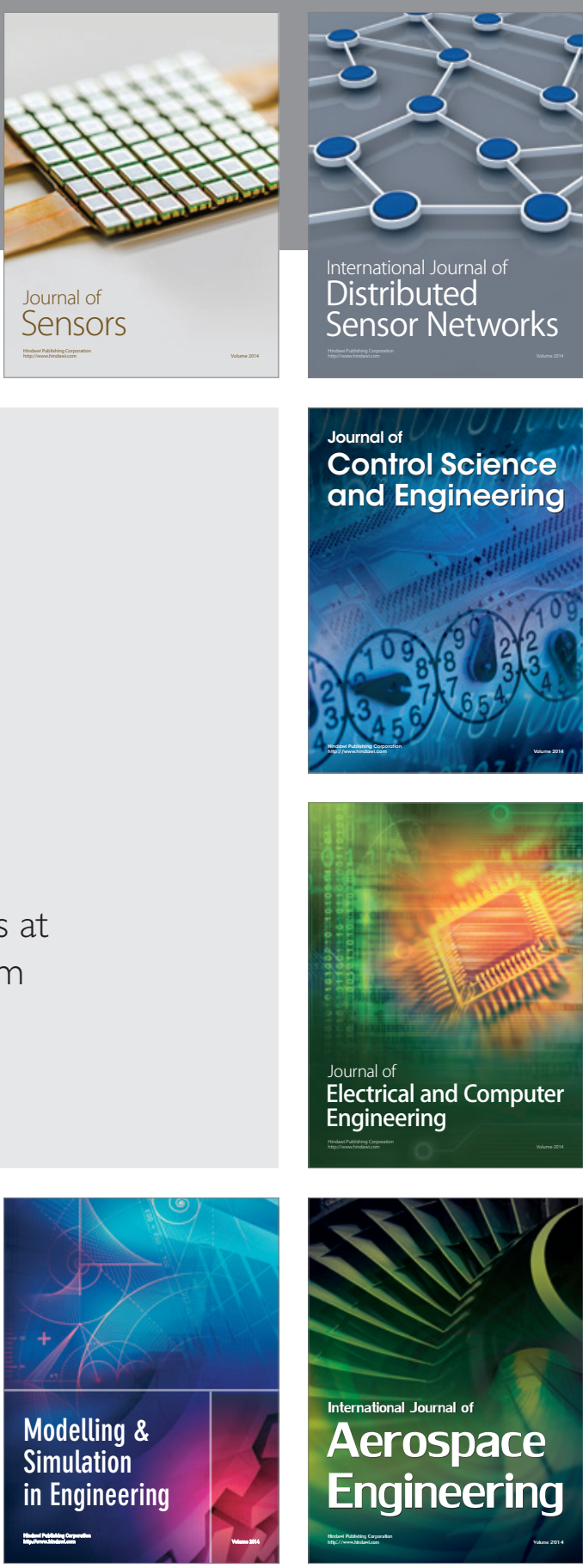

International Journal of

Distributed

Sensor Networks

Journal of

Control Science

and Engineering
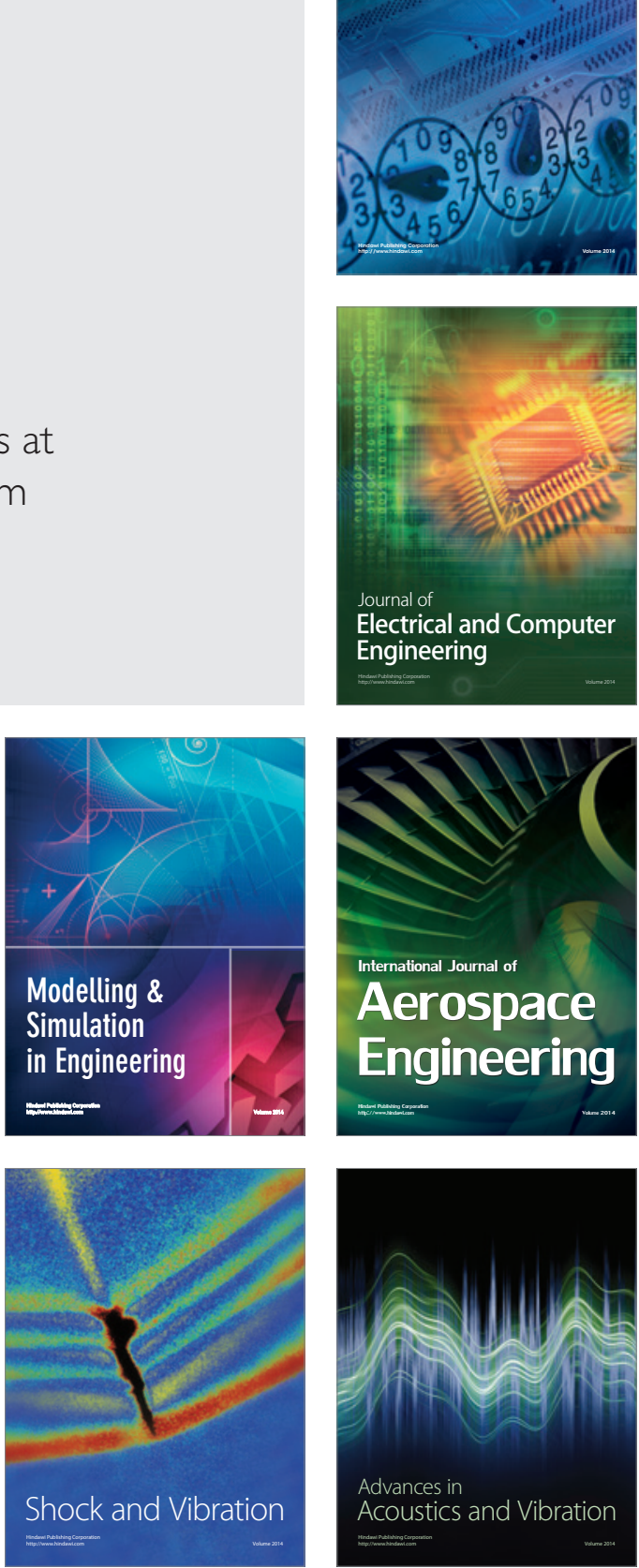